\title{
Karaciğerde Granülomatöz Enfeksiyon Zemininde Gelişen Hepatolitiazis: Olgu Sunumu
}

\section{Hepatolithiasis in Liver Based on Granulomatous Infection: Case Report}

\author{
Arda Şakir YILMAZ ${ }^{1}$, Mustafa SALIŞ${ }^{1}$ \\ ${ }^{1}$ Eskişehir Osmangazi Üniversitesi Tip Fakültesi Genel Cerrahi Kliniği, Eskişehir
}

$\overline{\mathbf{O ̈ z}}$

İntrahepatik safra kanallarında taş oluşumu hepatolitiazis olarak adlandırılır. Enfeksiyonlar, safra stazı ve diyet gibi çevresel faktörler hepatolitiazis oluşumunda etkendir. Lokal karaciğer tüberkülozu nadir görülmesine karşın olgumuzda hepatolitiazis ile birlikteliğini göstermeyi amaçladık.

Anahtar Kelimeler: Granülomatöz Enfeksiyon, Hepatolitiazis, Tüberküloz

\section{Giriş}

İntrahepatik safra kanallarında taş oluşumu hepatolitiazis olarak adlandırılır. Hepatolitiazis veya intrahepatik taşlar batı dünyasından ziyade Doğu Asya ülkelerinde daha sık görülürler. Bu arada ülkemizde de nadiren görülebilmektedir. Rölatif insidans batı ülkelerinde yaklaşık \%1 iken bu oran Tayvan, Güney Kore ve Çin'de sırasiyla $\% 20, \% 18$ ve \%38-45 olarak rapor edilmektedir (1). Patogenez tam olarak bilinmemektedir. S1k kolanjit ataklarının meydana gelmesi, taşların komple eksizyonunun güçlüğü ve kolanjiyo-karsinoma gelişimi ile olabilen muhtemel beraberliği nedeniyle ciddi bir sağlık problemidir (2). Hepatolitiazise neden olan mekanizmalar henüz net anlaşılamamış olsa bile bakteriyel enfeksiyonlar, safra stazı ve parazitik enfestasyonlar ile diyet gibi çevresel faktörler suçlanmaktadır $(3,4)$.

Karaciğer tüberkülozu genellikle miliyer pulmoner hastalık ile biraradadır; fokal karaciğer tüberkülozu ise nadir bir formdur (5).

Leader 1952 yılında dünya literatürünü gözden geçirerek yalnızca 80 lokalize karaciğer tüberkülozu olgusu saptamış ve karaciğer tüberkülozunu miliyer ve lokal olmak üzere iki formda sınıflandırmıştır. Lokal hepatik tüberküloz ise hepatik apse veya tüberkülomlar şeklinde görülebilen fokal veya nodüler formile intrahepatik kanalları tutan tübüler formdan oluşur (6).

\begin{tabular}{ll}
\hline & ORCID No \\
Arda Şakir YILMAZ & 0000-0003-1269-0814 \\
Mustafa SALIŞ & \\
& \\
Başvuru Tarihi / Received: & 28.07 .2019 \\
Kabul Tarihi / Accepted : & 10.04 .2020 \\
Adres / Correspondence $:$ & Mustafa SALIŞ \\
Eskişehir Osmangazi Üniversitesi Eğitim Araştırma Uygulama \\
Hastanesi Genel Cerrahi Polikliniği, Eskişehir \\
e-posta / e-mail $\quad: \quad$ salismustafa@gmail.com
\end{tabular}

\section{Abstract}

Stone formation in intrahepatic bile ducts is called hepatolithiasis. Environmental factors such as infections, bile stasis and diet are the factors in the formation of hepatolithiasis. Although local liver tuberculosis was rare, we aimed to demonstrate the association of hepatolithiasis with our case.

Keywords: Granulomatous Infection, Hepatolithiasis, Tuberculosis

Karaciğer tüberkülozunun oluşmasında muhtemel mekanizmalardan ilki mikro-organizmanın akciğerdeki tüberküloz odağından (hastalık saptandığında aktif veya inaktif olabilir) hematojen yolla (hepatik arter ile) karaciğere ulaşmasıdır. Diğer mekanizmalar ise, eş zamanlı olarak gastrointestinal sistemde varolan infeksiyonun portal ven aracılığıyla karaciğere yayılması, ya da M. tuberculosis'in lenfatik yayımla karaciğere ulaşmasıdır (7).

Olgumuzda ise hepatolitiazis ilelokal karaciğer tüberkülozunun birlikteliğini sunmayı amaçladık.

\section{Olgu Sunumu}

57 yaşında kadın hasta, sağ üst kadran ağrısı ara ara olan kusma şikayetleri nedeniyle kliniğimize başvurdu. Fizik muayenesinde sağ üst kadranda hassasiyet dışında patoloji olmayan hastanın laboratuvar tetkiklerinde beyaz küre 7000/mm3, hemoglobin 11,8 g/dl, AST:25 U/L(0-31 U/L), ALT:29 U/L (0-33U/L), T. Bil:0.83 mg/dL (0-1.1 $\mathrm{mg} / \mathrm{dl})$, D. Bil:0.14 mg/dL (0-0.2 mg/dl), kreatinin $1,08 \mathrm{mg} / \mathrm{dl}$ olarak görüldü. Bunların dışındaki rutin laboratuvar testleri normaldi. 7 yil önce kolesistektomi operasyonu olan hastanın yapilan abdomen USG sinde karaciğer segment 6 düzeyinde intrahepatik safra yollarında $1 \mathrm{~cm}$ 'ye ulaşan genişleme ve hava ekojeniteleri izlendi. Yapilan Magnetik Rezonans Kolanjiyo Pankreatografi (MRCP) de ise yine segment 6 seviyesinde safra yollarında fokal genişleme dikkati çekmiş olup, safra yolları içerisinde tübüler form kazanan ve dallanan hipointens alanlar dikkati çekmiş ve intrahepatik safra yollarında hiperintens lezyonlar tespit edildi. Porta hepatis seviyesinde, gastrohepatik ve paraçölyak lokalizasyonda belirginleşmiş lenf nodları görüldü (Şekil.1).

Hasta hepatolitiazis ön tanısı ile operasyona alındı.Intraoperatif Ultrasonografi (USG) eşliğinde segment 6 rezeksiyonu yapıld1. Spesmenin patolojik 
incelemesinde portal alanlarda granülom yapıları görüldü. Bazı granülomlarda koagülatif nekroz alanları, birkaç granülomda tüberküloz basili görüldü ve tüberküloz enfeksiyonu açısından anlamlı olduğu sonucuna varıldı. Diğer sahalarda safra duktus yapılarında dilatasyon ve hepatolitiazis izlendi.Ayrica hastaya thoraks bilgisyarlı tomografi çekilerek, göğüs hastalıklarına akciğer tüberkülozu açısından konsülte edildi.

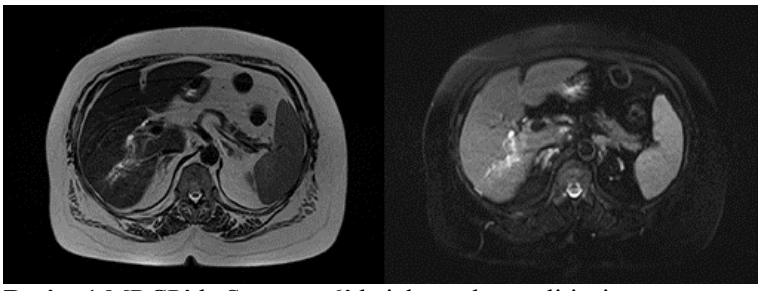

Resim.1 MRCP'de Segment 6'da izlenen hepatolitiazis

\section{Tartışma}

Hepatolitiazis ilk olarak 1906 y1lında Vachell ve Stevens tarafindan tanımlanmıştır (8). Safra yolları bifurkasyonunun proksimalinde taş bulunması ile karakterize bir hastalıktır. Uzakdoğu ülkelerinde daha sık görülmektedir ve taşlar hemolitik hastalıklar, intrahepatik safra yolu striktürleri, sklerozan kolanjit ve parazitik enfestasyonlar gibi safra stazına bağlı nedenlerle oluşurlar. Batı ülkelerinde ise taşlar safra kesesi kaynaklıdır ve duktus sistikustan intrahepatik safra yollarına ulaşırlar (9). Hepatolitiazis vakalarının neredeyse tamamında bakteriyel enfeksiyon mevcuttur ve enterik bakteri kolonizasyonu gösterilmiştir (10). Günümüzde doğru preoperif tanı konulabilmesi için çeşitli görüntüleme yöntemlerinden faydalanılmaktadır. Abdominal ultrasonografi, bilgisayarlı tomografi ve manyetik rezonans yöntemleri ile karaciğerin etkilenen bölümündeki atrofi düzeyi belirlenmektedir. MRCP, perkütan transhepatik kolanjiografi ve endoskopik retrograt kolanjiografi tetkikleri ile intra ve ekstrahepatik safra yolu anatomisi ve taşların yerleşimi ile ilgili net bilgilere ulaşılmaktadır (3). Olgumuzda tanı MRCP ile konularak operasyon sonrası patoloji ile kanıtlanmiștır.

Primer karaciğer tüberkülozu ve tüberkülomu literatürde sporadik olarak rapor edilmiş ve bunların büyük çoğunluğu küçük yuvarlak tüberkül veya abseler şeklinde tariflenmiştir (12,13). Literatürde safra yolları tıkanıklığının nedeni olarak karaciğer tüberkülomu incelendiğinde çok az sayıda olgu bildirilmiştir (14).

Hepatik tüberkülozun tanısında abdominal USG ve BT gibi görüntüleme yöntemleri yardımcıdır (12). Abdominal USG'de çoğunlukla hipoekoik lezyonlar ve kompleks kitleler saptanırken, abdominal BT'de ise soliter veya multipl fokal kitleler görülebilir. Ayrıca, piyojenik karaciğer apsesi ve amip apsesinin de ayırıcı tanıda düşünülmesi gerekir. Hastamızın MRCP'sinde segment 6'da görülen hepatolitiazis ve porta hepatis çevresindeki lenf nodları haricinde patolojik bulgu yoktu. Olgumuzda gastrointestinal sistemde başka bir tüberküloz odağının saptanmamış olması nedeniyle, geçerli mekanizmanın, primer tüberkülozun hematojen yayılımı ve karaciğerde reaktivasyonu olabileceğini düşünmekteyiz.

Hepatolitiazisin tedavisi temelde cerrahidir, metodun seçiminde intrahepatik kanalların morfolojisi, darlığın yeri ve taşların lokalizasyonları önemlidir. Geçmiş yıllarda seçilmiş hastalarda primer tiplerin artmasıyla karaciğer rezeksiyonları oranları artmıştır. Buna rağmen seçilmiş hastalarda ERCP ile nazobiliyer dren uygulamasını takiben irrigasyon da bir tedavi metodu olarak karşımıza çıkmaktadır. Radyolojik, cerrahi ve endoskopik yaklaşım intrahepatik taşların tedavisinde sıklıkla kullanılan etkili metodlardır (15).

Olgumuzdaki tedavi seçeneği cerrahi olarak planland 1 ve segmentektomi ile hepatolitiazis tedavisi yapıldı. Bilindiği üzere hepatolitiazis gelişimi enfeksiyona sekonder oluşabileceği gibi tüberkülozun yaygın olduğu ülkemizde henüz kanıtlanmasa da lokal karaciğer tüberkülozunun intrahepatik safra yollarında tıkanmaya neden olabileceğini akla getirmektedir.

Hasta Onamı: Hastadan vaka takdimi yapılacağına dair aydınlatılmış onam formu 15.06.2019 tarihinde alınmıştır.

\section{Kaynaklar}

1. Nakayama F.Hepatolitiazis and Cholangiohepatitis. In: Gallstones Cohen S, Soloway RD eds. Churchill Livingstone, NewYork, 1985;237- 246.

2. Chen MF, Jan YY, Wang CS, Jeng LBB, Hwang TL, Chen. Intrahepatic stones associated with cholangiocarcinoma. Am J Gastroenterol. 1989;84:391-5.

3. Kamiya J, Kitagawa Y, Nimura Y. Intrahepatic Stones. In Blumgart LH, Fong Y (Eds). Blumgart's Surgery of the Liver and Biliary Tract. 3rd ed. London: WB Saunders; 2000,815-826.

4. Yellin AE, Donovan AJ. Biliary lithiasis and helminthiasis. Am J Surg. 1981;142:128-36.

5. Nak SG. Karaciğer tüberkülozu. In: Özyardımcı N, ed. Akciğer ve akciğer dışı organ tüberkülozları. Bursa, Uludağ Üniversitesi Basımevi: 1999:293-306.

6. Leader SA. Tuberculosis of the liver and gall bladder with abscess formation. A review and case report. Ann Intern Med. 1952;37:594-606.

7. Alvarez SZ. Hepatobiliary tuberculosis (Review). J Gastroenterol Hepatol. 1998;13:833-9.

8. Vachell HR, Stevens WM. Case of intrahepatic calculi. Br Med J. 1906;1:434-6.

9. Nitin Rao AR, Chui AK. Intrahepatic stones - an etiological quagmire. Indian J Gastroenterol. 2004;23:201-2.

10. Sheen-Chen S, Chen W, Eng H, Sheen C, Chou F, Cheng Y, Lee T. Bacteriology and antimicrobial choices in hepatolithiasis . Am J Infect Control. 2000;28:298-301.

11. Kitagawa $\mathrm{Y}$, Nimura $\mathrm{Y}$, Hayakawa $\mathrm{N}$, et al. Intrahepatic segmental bile duct patterns in hepatolithiasis: a comparative cholangiographic study between Taiwan and Japan. J Hepatobiliary Pancreat Surg 2003;10:377-1.

12. Berbard E, Pelissier E, Birtwisley, et al. Tuberculose hepatique a forme pseudo-tumorale. A propos d'une observation. Ann Gastro Enterol Hepatol .1985;21:135. 
13. Brauner M, Buffard MD, Jeantils V, et al: Sonography and computed tomography of macroscopic tuberculosis of the liver. J Clin Ultrasound. 1989;17:563.

14. Wee A, Nilsson B, Wang TL, et al: Tuberculous pseudotumor causing biliary obstruction. Acta Cytol. $1995 ; 39: 559$
15. Kuo-Shyang J, Treatment of intrahepatic biliary strictures associated with hepatolithiasis. Hepatogastroenterol. 1997; $44: 342-50$ 